\title{
How Subjectivity can be Investigated in the Post-rationalist Cognitive Approach: Clinical and Psycho-diagnostic Tools
}

\author{
Bernardo Nardi $^{1}$, Emidio Arimatea ${ }^{1}$, Mirta Vernice ${ }^{2} \&$ Cesario Bellantuono ${ }^{1}$ \\ ${ }^{1}$ Department of Experimental and Clinical Medicine, Polytechnic University of Marche, Ancona, Italy \\ ${ }^{2}$ Department of Psychology, University of Milano-Bicocca, Milano, Italy \\ Correspondence: Bernardo Nardi, Department of Experimental and Clinical Medicine, Polytechnic University of \\ Marche, Via Tronto 10/A, Torrette di Ancona, 60126, Italy. Tel: 39-71-220-6019. E-mail: b.nardi@univpm.it
}

\author{
Received: March 3, 2012 Accepted: April 12, 2012 Published: June 1, 2012 \\ doi:10.5539/ijps.v4n2p174 \\ URL: http://dx.doi.org/10.5539/ijps.v4n2p174
}

\begin{abstract}
Reciprocity with primary care-givers affects subjects' adaptive abilities towards the construction of the most useful Personal Meaning Organization (PMO) with respect to their developmental environment. Over the last ten years we analyzed the post-rationalist approach focusing on the construction of a specific framework for distinguishing immediate experience from explanations of the experience, the slow-motion ("moviola") technique, and the analysis of awareness and resistance. Neuroimaging (functional Magnetic Resonance Imaging, fMRI), genetic polymorphism investigations and new psychodiagnostic post-rationalist tests (Mini Questionnaire of Personal Organization, MQPO, and Post-Rationalist Projective Reactive, PRPR) were used to conduct a scientific in vivo study of PMO. The presence of specific and stable clinical patterns both in inward and outward subjects was supported by parallel differences in cerebral activation during emotional tasks at fMRI and in the different expression of some polymorphisms concerning serotonin pathways; Furthermore, validation data concerning both a questionnaire (as MQPO) and, crucially, a projective test (as PRPR) allowed to distinguish four organizational profiles, confirming their adaptive significance in assimilation of experience. Focusing on the PMO promotes the emergence of adaptive individual resources, thereby improving skills needed to control perturbing emotions and to apply more flexible behaviour strategies.
\end{abstract}

Keywords: Post-Rationalist Cognitive (PRC) therapy, Personal Meaning Organizations (PMO), Functional neuroimaging (fNI), Single Nucleotide Polymorphism (SNP), Mini Questionnaire of Personal Organization (MQPO), Post-Rationalist Projective Reactive (PRPR)

\section{Post-rationalist Theoretical and Clinical Frameworks}

Among constructivist approaches to psychotherapy, the post-rationalist paradigm constitutes one of the most innovative, proposing a useful epistemological theory of mental functioning with successful applications in clinical practice. As known, this model was conceptualized by Vittorio F. Guidano in the Eighties (Guidano \& Liotti, 1983; Guidano, 1987, 1991a, b, 1995). Such an approach originates "from the perception of a discrepancy between the promising results of a psychotherapeutic practice making wide use of behaviour therapy techniques and the limited explicative power of the learning principles forming the theoretical foundation of those techniques". According to the development of the epistemology of complexity and the evolutionary, explanatory and holistic psychological approaches (Weimer, 1979, 1982; Prigogine, 1980; Sameroff, 1982), it is possible to focus on individual self-organization and self-determination as consequent to openness and plasticity of his/her developmental pathways. By this point of view, the self can be investigated not as an entity connecting experience and behaviour, but as a process of selfhood, with a reflexive nature, continuously remodelling and restructuring itself (Guidano, 1987).

As Guidano wrote (1987), “individuals' experiences, both positive and negative, are powerfully influenced by their personal 'psychological organizations"'. Therefore, "the 'deep structure' or 'core organizing processes' that constrain human psychological experience may be at the heart of successful interventions as well the classical problem of resistance, relapse, and refractory behaviors ... Those psychological processes involved in the development and maintenance of personal identity or 'self' should be the primary focus of research and intervention in psychological disorders". For this goal, his post-rationalist approach drew together themes from object relations theory, ego psychology, attachment theory, constructivist models of human cognition, and 
lifespan developmental psychology. From this evolutionary, holistic and process-oriented perspective to living systems, a special attention must be directed to the hierarchical organization, temporal becoming and dynamic equilibrium by which the human knowing system can be considered as a self-referent complexity, with self-organizing ability. This ability has a basic evolutionary constraint that "through the maturational ascension of higher cognitive abilities, progressively structures a full sense of self-identity with inherent feelings of uniqueness and historical continuity. The availability of this stable and structured self-identity permits continuous and coherent self-perception and self-evaluation in the face of temporal becoming and mutable reality. For this reason, the maintenance of one's perceived identity becomes as important as life itself'.

The main head points of Guidano's theory are: a) the importance of subject's manner of arranging and self referring immediate experience to construct self identity and the lack of centrality and impartiality of therapist-observer (knowledge is seen from the point of view of the experiencing subject), b) the interdependence between subjective and objective, emotional and cognitive, experienced and explained as constitutive of any human knowing process, and c) the therapist as a "strategically oriented perturber", helping the subject to reach a more adaptive mental functioning; however, this result can be obtained only into the borders of his/her invariant modalities structured during development. There are "core organizing processes" on the basis of every human psychological - both physiological and pathological - experience. Furthermore, the conceptualization of "Personal Meaning Organization" (PMO) individuates "the specific arrangement of personal meaning processes by which each individual is provided with a sense of oneness and historical continuity in the course of his/her lifespan" (Guidano, 1987).

In clinical practice, knowledge of the "self system" deeply influences therapist's attitude, assessment procedures, self-observation method, and the structure and dynamics of therapeutic change; furthermore, it allows a subject-centred reconstruction of immediate experiencing, modifying dysfunctional patterns of self-perception. Constructing the therapeutic setting, centred on the subjective manner in self-referring experience, Guidano proposed the slow-motion ("moviola") setting, that consists in instructing clients to focus, in a significant scene, on the difference between "immediate experiencing" ("what" happens and "how" it happens) and "explanations" ("why" something happens) before, during and after the scene. In particular, "the "how" has to do with the subjective experiencing, both in terms of how it is made up, that is, its ingredients (e.g., ongoing patterns of flowing imagery; multifaceted, opposing feelings; the felt sense of self) and in terms of how it comes about, that is, what perception of events or circumstances brought it on" (Guidano, 1991a). From such an evolutionary point of view, the possibility of distinguishing these two levels of experience is useful to focus knowledge and it is related to the emergence of language and cerebral hemispheres specialization in humans. According to Pribram's observation (1971), by which neural events show two different manners in processing and transmitting information (i.e., continuous or discrete and intermittent activities), immediate experiencing and explanations of experience correspond, respectively, to the "tacit" and "explicit" levels of knowing: the first one, as the intrinsic and holographic (global, implicit and widely unconscious) knowledge; the second one, as the analytic and rational (analytical, explicit and conscious) knowledge. By this point of view, the therapist does not consider the achievement of a therapeutic goal as a matter of choosing the "right" technique, but rather, s/he has the strategy of driving the client's processes to make the tacit explicit. In this way, the therapist can do more than help subjects in changing their dysfunctional behaviours. In fact, by directing therapy toward core emotional themes and using the interactional aspects of the therapeutic relationship, it is possible to modify clients' core patterns of self-perception and, thereby, to obtain substantive and lasting change (Guidano, 1987, 1991a).

Despite of successful application in clinical practice, both with neurotic and psychotic patients, only few scientific researches were produced to improve the PMO paradigm. Furthermore, attachment was taken as direct referring, despite the fact that univocal references from the two models do not exist.

In the latest years, the development in neurosciences provided PMO with the conceptualization of new physiological and adaptive possible references. Moving from the concept of PMO, Nardi - who was a Guidano's fellow - proposed a new interpretation of the adaptive meaning of the different personality styles, both during the evolution of homo sapiens and the development of every person. Main theme of this approach is that in sapiens' evolution the appearance of a specific PMO allows the best adaptation possible in one's environment, constructing the most useful attachment and reciprocity that are possible. To underline the physiological significance of PMO evolution, he introduced a new terminology to indicate the Guidano's main PMO: "Controller" (for the Guidano's "Phobic" PMO), "Detached" (for the Guidano's "Depressive" PMO), "Contextualized" (for the Guidano's "Psychogenic Eating Disorders" PMO), and "Principle-Oriented" (for the Guidano's "Obsessive" PMO); the main aspects of these PMO were described later. Therefore, reciprocity with the primary care-givers drives individual adaptive abilities towards the construction of the most useful PMO with 
respect to the own developmental environment (Nardi, 2007, 2010; Nardi \& Bellantuono, 2008).

As Nardi highlighted, there are two primary developmental axes in driving the adaptive stabilization of the subject's PMO.

The first axis drives the stabilization of PMO depending on how the child perceives the care-giver's behaviour, ad specifically if $\mathrm{s} / \mathrm{he}$ is predictable or not (i.e., if it is the same in overlapping situations).

In particular, in overlapping situations concerning laugh, angry, fear, surprise, tiredness, etc., the child perceives how the care-giver (and, in general, his/her environment) is present, available, reliable, constant, and predictable. These aspects allow: a) to recognize and predict experience precociously and univocally, b) to decode care-giver's and self facial expressions concerning basic feelings (fear, anger, surprise, sadness, and happiness) and emotional schemata. Focusing on such activations allows to define some "nuclear scenes" that become bases of his/her proto self (Tomkins, 1978; Abelson, 1981); these "isles" of experience gradually join together defining a kind of "movie in the brain" (Damasio, 1999) and constituting the bases of identity. Therefore, constancy and predictability of care-giver's behaviours and emotional expressions allow a precocious decoding of his/her own similar activations and a synchronization of care-giver and child psycho-physiological rhythms. For example, the subject begins to perceive in which situations $\mathrm{s} / \mathrm{he}$ feels safe or in danger, protected or alone and, therefore, $\mathrm{s} / \mathrm{he}$ reads through his/her internal activations what happens in the environment ("inward" focus).

On the contrary, when the care-giver's behaviours and expressions are perceived as more complex and changing, depending from external situations and social context (of which the child has still not the ability of being aware), they result less predictable and more difficult to decode. Therefore, the child needs to memorize new and more complex data and needs to update them; also nuclear scenes must be updated and reframed in several and different cases; thus, emotional activations require to be connected to a self-evaluating cognitive schemata (i.e., guilt, sense of self-inadequacy, shame, pride, and fulfilment). In these conditions, the self develops moving from a preliminary evaluation of environmental messages and requests, driving recognition of internal activations and self-perception ("outward" focus).

Therefore, both in inward and outward focus, the care-giver's (and, more in general, environment's) predictability drives each individual to reach the better possible adaptation; likewise, the level of predictability is a basic factor to construct invariant skills in assimilating and self-referring experience, and to maintain internal coherence, in inward or in outward manner. In fact, there is not an adaptive pre-eminence of inward or outward focus, but each one provides specific skills in decoding self and environment, in relation with the main aspects perceived through attachment. Obviously, inward/outward patterns are along the same process-oriented axis of development; therefore, they appear more or less evident in different subjects, but in each individual one of the two is in any case prevalent, at least in specific categories of experience.

Inward focus develops because it is useful when external world is perceived as stable, predictable, and, therefore, its changes can be easily decoded in terms of physic protection or loneliness. Activations consist essentially of basic feelings, that don't need complex cognitive evaluation to be expressed, while cognitive processes consist in following, explaining and self referring the feeling perceived (i.e., why the subject feels him/herself frightened or sad). Precocious decoding of specific basic feelings in the same situations allows the child - once stabilized the emotional recognizing of that kind of situation - to avoid looking at the care-giver also in similar circumstances. During development, the faculty of using internal activations to decode any new situation is stabilized and extended. The subject, becoming able to manage a situation, increases confidence in his/her abilities and inhibits the fear system, even if the situation can be dangerous or if the care-giver seems worried: in fact, in this case, the care-giver's expression is read as evidence of love and not as of real risk or of mistrust. Therefore, same emotional reciprocity patterns are expressed in the same situations till ability in manage these situations becomes higher: coping changes is conditioned by one's own perceived managing skills. Communication is centred on physical reciprocity: distance, availability of care-giver in terms of protection or detachment.

Outward focus, on the contrary, develops because it is suitable when environmental characteristics seem vague, complex or changing and, therefore, needing assimilation of more cognitive parameters. The care-giver's low predictability depends on the fact that $\mathrm{s} / \mathrm{he}$ pays attention to the social context and its rules; therefore, the care-giver behaviour changes depending where $\mathrm{s} / \mathrm{he}$ is or with whom $\mathrm{s} / \mathrm{he}$ is. In these cases, perceiving the care-giver as less predictable, the child must focus on the care-giver to decode the situation and, consequently, to verify if his/her own behaviour is correct or not and if $s /$ he must change it. In these cases, when there are not emergency situations for surviving, cognitive self evaluation is essential to perceive emotions, that are more complex and expressed as emotional schemata (i.e., pride, shame or guilt needs a preliminary evaluation of one's own behaviour). Complexity and variability or ambivalence of environmental signals orientate the construction 
of emotional schemata through a relevant importance of cognitive self-evaluation. The subject learns to read information from his/her significant environment to update internal perceptions, in terms of acceptance or refusal, high or low amiability, and importance or insignificance. Communication is centred on semantic reciprocity, in terms of approval, decoding, rules, and values; therefore, reciprocity develops along a process-oriented axis, from high to low patterns of semantic reciprocity.

The second axis drives the adaptive stabilization of the subject's PMO depending on how close or distant the child perceives the care-giver's behaviour: more specifically, if the care-giver is available, helpful and willing or not (i.e., if there is or not the property of receiving care, help, support, and sympathy).

From the care-giver's helpfulness depends the construction of high or low reciprocity (high protections and reassurance; frequent expressions of approval or disapproval - low protection and reassurance, with consequent feeling of loneliness; rules and precepts instead of constant approval or disapproval).

The high helpfulness development allows to centre behaviour on perceiving and managing how one is protected, considered and valued, orienting consequently his/her exploratory detachment. Subjects can handle situations of proximity, availability of help, dependence, other's requests and social sharing. The inward developments based on high helpfulness and reciprocity learn to construct identity individuating sure and reliable figures, discriminating friend or enemy people and groups, and managing adversities and dangers. On the contrary, the outward developments based on high helpfulness and reciprocity learn to construct identity by focusing on others' internal world. In this way, it is possible to promote the ability in using, choosing, coping and, if it is possible, anticipating external judgements and opinions, producing successful behaviours, and to update them when styles and patterns are changing.

The low helpfulness development allows to centre behaviour on perceiving and managing how one is alone or driven to assume a responsibility on him/herself, orienting consequently his/her exploratory detachment. Subjects can handle situations of distance, unavailability of help, independence, needs of personal commitment and social isolation. The inward developments based on low helpfulness and reciprocity learn to construct identity coping with separation, loss, desertion, perceiving loneliness as the starting point to develop one's own abilities, to become aware of one's own responsibilities, and also to take care of others. On the contrary, the outward developments based on low helpfulness and reciprocity learn to construct identity by finding rules of good, right and straight conduct, reordering experience despite the contradictions observed and one's own cognitive limits.

Thanks the two above mentioned primary developmental axes (concerning care-giver's predictability and helpfulness, respectively), four main PMO becomes stable (see Table 1).

1) In inward development, when both care-giver's predictability and helpfulness are high (not depending on the quality - positive or negative - of significant relationships), reciprocity is essentially physical and identity is constructed controlling how the subject perceives his/her need of protection or freedom: separation from care-giver and environmental exploration are possible when the subject feels the situation under control and, therefore, when s/he is sure of him/herself. In all these cases, that are inward with high physical reciprocity, the "Controller" PMO becomes stable.

2) In inward development, when care-giver's predictability is high but helpfulness is low (not depending on the quality - positive or negative - of significant relationships), reciprocity is essentially physical and identity is constructed managing detachment and loneliness that the subject perceives as the habitual condition of his/her life-span, trying to find the necessary resources to realize him/herself. In all these cases, that are inward with low physical reciprocity, the "Detached" $P M O$ become stable.

3) In outward development, when care-giver's predictability is low but helpfulness is high (not depending on quality — positive or negative — of the relationships), reciprocity is essentially semantic and identity is constructed "in real-time", step by step, basing on signals perceived from the external context, in terms of approval or disapproval, agreement or disagreement, and success or failure. A relevant importance is given to comparison with others, to the results achieved and to the adaptive research of persons, situations, and activities which enable to draw the better self-esteem possible. In all these cases, that are outward with high semantic reciprocity, the "Contextualized" $P M O$ become stable.

4) In outward development, when both care-giver's predictability and helpfulness are low (not depending on quality - positive or negative — of the relationships), reciprocity is essentially semantic and identity is constructed on precepts, rules, criteria about what is right or wrong, good or bad, and useful or useless. The subject drives his/her strategies to individuate a set of positive thought and behaviours, to reach certainties 
stabilizing perception of the self and the world, and, at the same time, to keep out negative thoughts and behaviours. The fundamental parameters to evaluate his/her behaviour are not the results (as for contextualized outwards), but the self-commitment. Research of reciprocity (consistent with own emotional self-evaluative schemata) is performed evaluating if it is according to his/her own values; the subject appears consenting to instructions and rules, but s/he is also looking for a new and original theory on life, concerning significance of skills, relations, and goals. In all these cases, that are outward with high semantic reciprocity, the "Principle-Oriented" PMO become stable.

Therefore, each individual has variable and constant modalities of self referring experience, typical of each specific PMO; however, in many cases, it is possible to observe that a subject can show secondary modalities, evident in some situations during the life-span, that are typical of another PMO ("combined organizations"). This is possible when the subject grows up with significant adults having different organizations (i.e., father with an inward organization, mother with an outward organization). For example, the subject can present a prevalent inward Controller organizational component, with a main theme of evaluating environmental dangerousness, and a secondary outward Contextualized component, with a judgement theme: in this case, the subject can avoid a frightening situation in which his/her distress can be produced also by other's negative opinion.

Table 1. Main clinical features, concerning Inward or Outward experience focus (Nardi, Rezzonico, \& Bellantuono, 2010)

\begin{tabular}{llll}
\hline \multicolumn{1}{c}{ Main Clinical Features } & \multicolumn{1}{c}{ Inward Subjects } & \multicolumn{2}{c}{ Outward Subjects } \\
\hline $\begin{array}{l}\text { Perception of care-giver } \\
\text { attitude (attachment) }\end{array}$ & $\begin{array}{l}\text { Predictable and recursive, centred on } \\
\text { the }\end{array}$ & $\begin{array}{l}\text { Less predictable and changing, } \\
\text { environmental }\end{array}$ & $\begin{array}{l}\text { surentress/dangerousness on environmental requests or } \\
\text { rules }\end{array}$
\end{tabular}

Stable patterns

Cognitive abilities

Reciprocity construction

Environmental control

High reciprocity Personal Controller PMO: balance between Meaning Organizations need of protection and freedom (PMO)

Low reciprocity Personal Detached PMO: balance between Meaning Organizations loneliness and self commitment (PMO) rage, sadness, happiness)

Pointed to practical and key aspects of life (evaluating dangerous changes, help availability and accessible coping abilities)

Based on perception of physical distance from others (i.e., their presence or absence, goodwill or hostility)

Adaptation ability in performing protection and availability of others, on the one hand, and loneliness and abandonment on the other
Use of internal activations (i.e., fear, Reading of external messages to rage) to read environment's realize internal adequacy or normality characteristics (i.e., if it is available, (i.e., if one is normal or not, good or dangerous, etc.)

Prevalence of basic feelings (fear, Prevalence of emotional schemata

bad, keep up with something or not, etc.)

(shame, blame, niceness, etc.)

Pointed to other thoughts and expectations, social rules, etc. (how to perform personal goals according to external requests and internal criteria)

Based on perception of semantic significance of environmental messages (i.e., as parameter of one's own personal attitude toward others or of intrinsic self value)

Adaptation ability in reaching approval and agreement, on one hand, and focus certainties, good rules and values on the other

Contextualized PMO: balance between approval and disapproval, agreement or disagreement, and success or failure

Principle-Oriented PMO: balance in constructing a correct view of the world choosing between antithetical aspect of life

Each PMO expresses adaptation abilities, allowing coping with life span situations; by the other side, each PMO can present a fragility, when perturbing environmental stimuli cannot integrate to the sense of self. However, a perception more positive or negative of self is not directly related to a specific PMO, but to personal fragilities in experience assimilation; in any case, themes of self referring narrations are consistent with the specific 
modalities of each PMO (i.e., inadequacy in contextualized PMO) and recognition of the specific organizational modalities of the subject allows to the therapist to reorder the subject's experience in a more adaptive manner. Furthermore, the post-rationalist approach provides the therapist of an adaptive key to read mental disorders, in which symptoms still represent an adaptation effort in difficult, instable, and fragile conditions of making experience. Therefore, during psychotherapeutic work, by focusing on the PMO it is possible to recognize and pull out adaptive individual resources, improving skills to handle perturbing emotions and find new and more flexible behaviour strategies.

In fact, the goal of therapy is not simply to eliminate symptoms (which often recur in another form); on the contrary, using them as a starting point, therapy reconstructs the specific subject's ability of self-referring experience, employing the adaptive skills of his/her PMO. By means of therapy it is then possible to read an experience from another point of view, consequently changing the emotional patterns associated with that experience.

According to Nardi (2010), through the "moviola setting", when a significant episode is chosen, the therapeutic work is similar to editing a movie, analysing what happens before (situations and behaviours generating the perturbing emotional activation), during (what the subject feels and how he/she refers it to himself/herself), and after the episode (which are the effects of what happened and of how the subject self-refers what happened? Can the subject normalize the activations experienced at the end of the episode and if so, how?). By means of the moviola setting, the episode can be roughly reconstructed from a general view (panning), which forms the basis for the therapeutic work during "film cutting". Single freeze-frames are chronologically reordered. The whole sequence is run through up and down, showing unknown or out-of-focus aspects and constructing a new, more integral and conscious knowledge of the self and others (reframing). The subject is requested to look again at the single freeze-frames, focusing both on what he/she felt (zooming in) and what others could have felt (zooming $o u t)$ in the same situation. Thus, starting from the clinical problem, it is possible to reconstruct the process dynamics of self-construction, identifying the related emotional and cognitive patterns. The subject learns that feeling and thinking is not the same process and acquires a decoding approach different from the one he/she usually employs; in particular, $\mathrm{s} / \mathrm{he}$ must consider that emotional activations during the immediate experience are more important than logical explanations by which he/she refers that experience to himself/herself. On the contrary, it is the current opinion that facts and thoughts are the core both of normal and pathological human behaviours.

From the first initial sessions the therapist involves the subject in an "exploratory co-operation", paying attention to the subjective way of reordering the immediate experience to construct personal explanations and believes. In this way, the external problem becomes internal. The subject is no longer a passive spectator of what happens ("I cannot do it", "I am not able", "I can't do anything"), but s/he realizes to be an active constructor of what $\mathrm{s} /$ he perceives and of how s/he self-refers the experience ("what my way of coping with the problem tells about me"). For example, s/he can discover the tendency: a) to control a dangerous world regarding his/her own need to be protected and to be free at the same time (in Controller PMO), b) to save himself/herself from the risk of abandonment, loss and failure (in Detached $P M O$ ), c) to research other persons' approval and agreement in situations perceived as personal examination to avoid disapproval and disagreement (in Contextualized PMO), or d) to research safety and certainty with respect to the antithetical aspects of experience, choosing the right manner to see life (in Principle-Oriented PMO). The consequence of this change is that the usual modality of self-referring the experience is seen only as one of the innumerable possible (and not always available) ways chosen and utilized by others. Therapeutic change is achieved by reordering the dialectics both regarding implicit and explicit knowledge and regarding the stabilization of organizational patterns and the changes allowed by flexibility of individual plasticity. In this process, any subject can develop a higher consciousness and, therefore, a more adaptive management of his/her emotional patterns.

By means of therapy, the "generative ability" can be improved, looking for new, more adaptive and alternative ways differing from the previous concepts, which were once perceived as necessary and unique to cope with life events. Changing one's personal managing skills is necessary to change and enlarge a perturbing feeling and discover new emotional activations. In other words, therapeutic change means to amplify the range of emotional managing skills, looking for new modalities to perceive the same situation. In the course of life, changes in thinking happen more quickly and flexibly than emotional changes. In fact, changes in opinion and life style can occur without perturbations, while it can be more difficult to manage emotional changes. As affective patterns are rather stable and less influenced by logical changes, the perturbing emotional experiences often produce a higher and quick internal coherence reorganization of thought processes. For example, in a Controller subject who is afraid of leaving his/her house, this fear can be reframed by a different and internal point of view 
including detachment from his/her reassuring figure: the subject can move from an initial perception of being sick (like in a "phobia") to a new perception of how s/he feels when $s /$ he is too far from or too near to his/her significant reassuring figure. To look at a situation from another point of view allows an enhancement of internal control regarding the fact that it is one thing to live with an unexplainable fear, but another to perceive this feeling as belonging to his/her own emotional pattern of approaches and splitting of which s/he is now aware. The awareness, in fact, consists in asking what is the effect of being himself/herself (immediate experience) and, therefore, how it is possible to make the immediate experience of being himself/herself consistent with the sense of the self (explanations of the experience). This effect depends on the PMO. Explaining the self-awareness (i.e., making it consistent with the sense of the self) allows the subject to integrate such awareness into the self-imago drawn from the immediate experience. This awareness does not correspond to rationality: it is a self-referring function allowing the subject to integrate experience data into his/her internal coherence, not to pursue the true reality.

Aim of this paper is to discuss the new tools provided by clinical and psycho-diagnostic post-rationalist adaptive model developed by our team.

\section{Neuroimaging Investigations}

Modern technologies of neuroimaging (especially functional Magnetic Resonance Imaging, fMRI and Positron Emission Tomography, PET) allow a scientific, real-time study of what happens when neurophysiological function swings into action or changes; likewise, it is now possible to study what happens when an emotion starts and which are the cerebral regions involved in this subjective activation. Using fMRI, a recent research of Bertolino et al. (2005) evaluated differences in individuals with different PMO (indicated as "Personality Styles"). In this study, in which personality styles were investigated by expert therapists of Institute of Post-Rationalist Psychology (IPRA; Mazzola et al., 2010), it was demonstrated that variability of amygdale activity is related to the personality style: in fact, looking facial expressions of fear, inwards subjects present a higher activation of amygdale, hippocampus and medial prefrontal cortex; on the contrary, outward subjects have a higher activation at level of fusiphorm gyrus, dorsal-lateral frontal cortex, and occipital cortex.

Another research of this group (Rubino et al., 2007), performed with 14 inward and 14 outward subjects during presentation of threatening stimuli, demonstrated an higher activation of medial prefrontal cortex in the inwards, as consequence of an higher neuronal recruitment during cognitive evaluation of primary emotions.

Recently, by using fMRI methodology, our research group investigated cerebral activations induced by standardized emotional stimuli in healthy subjects, both when the subject perceived facial expressions of an unknown person ("third person experience"), and when s/he perceived the same expressions on his/her own face ("first person experience") (Nardi \& Bellantuono, 2008; Nardi et al., 2008a, b). We studied amygdale and other nervous system structures activations in 10 healthy subjects. Subjects perceived emotional expressions by seeing an unknown face or their own face. Results were also matched with inward/outward organization (studied with clinical approach and MMPI2, Personal Meaning Questionnaire "PMQ", and "ad hoc" constructed Mini Questionnaire of Personal Organization "MQPO"). The research confirmed the importance of amygdale in the emotional stimuli processing, especially those with social impact, according to other neuroimaging investigations, performed with fMRI or PET scan (Breiter et al., 1996; Morris et al., 1996; Phillips et al., 1998; Whalen et al., 1998, 2001; Wang, Mc Carthy, Song, \& Labar, 2005; Costafreda, Brammer, David \& Fu, 2008; Pérez-Edgar et al., 2007). Referring to similar works, the presence of bilateral activations (Vuilleumier, Armony, Driver \& Dolan, 2003) or of the left amygdale activation (Morris et al., 1996) can be explained with the fact that subjects investigated could be inward or outward, performing different pattern of activation, as shown by Bertolino et al. (2005), Rubino et al. (2007) and our group (Nardi et al., 2008a, b).

As shown in Figure 1, inward subjects, with respect to the outwards, responded to anger with a more intense and univocal pattern; they mostly activated the right amygdale, and less cortical areas. According to other investigations, which demonstrated different activations between experience in first or third person (Vogeley et al., 2000; Schulte-Rüther, Markowitsch, Fink \& Piefke, 2007), in our study both inwards and outwards showed an higher activation for facial expressions of unknown people with respect to their own facial expressions, probably due to a "surprise effect" and an higher attention to aesthetic details not known with respect to the sight of their own image. When the subject sees his/her face generally, s/he activates both the amygdales. In presence of rage expressions, a higher activation of right amygdale could be explained by the fact that this emotion does not need a cortical semantic decoding for activation. Facial expressions of happiness activated left amygdale or both. Since the left amygdale is connected with language cortical systems, happiness seemed to be a more complex and less direct emotion, requiring a semantic codification. Therefore, all the three researches regarding PMOs 
(Bertolino et al. 2005; Rubino et al., 2007; Nardi et al., 2008a, b) demonstrated that inward or outward organizations have different patterns of emotional activation.
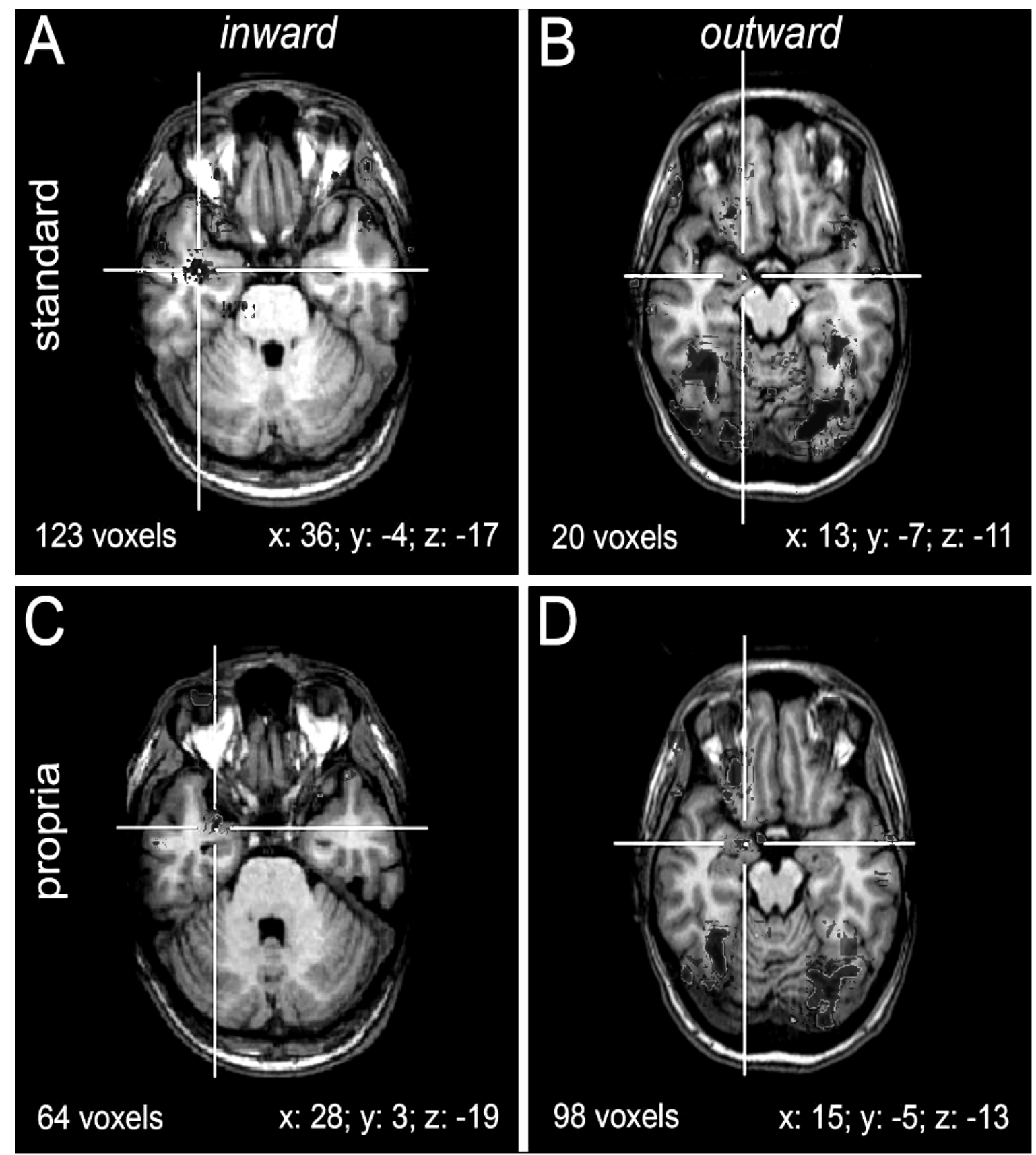

Figure 1. Different amygdale activations in inward and outward subjects

(Nardi, Rezzonico, \& Bellantuono, 2010)

Activation in the right amygdale, marked by intersection of two axes, produced by the presentation of facial expressions of anger. A, activation observed in a inward subject by presentation of unknown face expressing anger (third person experience); B, activation produced by the same stimulus in an outward subject; C, activation observed in the same inward subject of A observing his face (first person experience); D, activation produced by the same stimulus in the outward subject shown in B. According to radiological standard convention, left hemisphere is on the right side.

In the inwards subjects, rage activates more the right amygdale, according to the clinical experience that, in these individuals, the basic feelings (as rage) are predominant and they are used to decoding if environment is in a 
positive context or not. In our study, only in inward subjects a neutral facial expression activated amygdale (in higher rate in the case of their own face with respect to an unknown one). Also this fact confirms that inwards are centred on internal perceptions, moving from them to evaluate environmental situations: only by seeing his/her own face can produce to the inward subject an emotional activation.

On the contrary, outward subjects have a lower activation of amygdale but recruit more cerebral areas, both for rage and happiness facial expressions. For happiness, a higher activation of verbal hemisphere was observed in outwards, that have a higher semantic codification of emotions with respect to the inwards. Such results are in line with the clinical experience that inward subjects construct relations on physical reciprocity, while outward subject on semantic reciprocity.

\section{Genetic Investigations}

As known, in the latest years many works were carried out focusing on genetic differences among several individuals, concerning both normal and pathological behaviour. Furthermore, differences in phenotypic expressions of human genotype were studied to understand responses to pharmacological and/or psychotherapeutic treatment. In particular, the Single Nucleotide Polymorphism (SNP), that is the most common form of DNA sequence variations ( $>1 \%$ ), was investigated. In fact, in human genome, SNPs take place about every 1000 bases along the 3-billion-base genome. Even if many SNPs seem to have no effect on cell function, some SNPs may confer an individual susceptibility to develop diseases, determining their severity and progression, and affecting response to pathogens, toxins, and chemicals, or drugs and other therapies. Therefore, SNPs have become of great value for biomedical research in order to attain a personalized medicine. This approach will allow to recognize who could fall ill, of which disease, the most effective treatment, and the prognosis. Nevertheless, the huge number of polymorphisms to evaluate and the big number of experimental data necessary to obtain a significant assessment from the statistical analysis make these evaluations expensive and time consuming. Therefore, only few SNPs are usually selected for the genotyping in association studies.

Into post-rationalist framework, some recent papers have shown a correlation between some SNPs genotype and inward or outwards PMO Therefore, such data are according to the hypothesis that inward or outward PMO have also a specific genetic basis. This is a new interesting perspective to develop in next investigations, and can be useful to better understand psychotherapy's efficacy and its epistemological paradigms.

In the above mentioned investigation of Bertolino et al. (2005), different patterns in processing of fearful stimuli were discovered in the amygdale, depending by inward or outward personality style, in function of 5'HTTLPR polymorphism of serotonin transporter.

In our first-step research (Piva, Giulietti, Nardi, Bellantuono, \& Principato, 2010; Nardi et al., 2011a, b, c), we implemented bioinformatics methods for predicting the severity of a SNP and in evaluating which biological process could be affected. Another in-progress research of our research group (the Psychiatry, Biology and Genetics, and Law Medicine Units of the "Polytechnic University of Marche", Ancona, Italy) aims at investigating possible relations between SNPs concerning serotonin receptors and transporter, on the one hand, and inward or outward PMO, on the other, both in normal and in pathological conditions.

\section{Psycho-diagnostic Tests}

Recent theoretical developments on the post-rationalist cognitive model led to the development of different techniques of investigation about PMO. The first psycho-diagnostic instrument about PMO was the questionnaire "Personal Meaning Questionnaire" (PMQ) (Picardi, 2003) built on 68 items in the self-report arrangement. PMQ is a reliable and validated test, strictly based on Guidano PMO descriptions (see introduction) where the clinical experience had strongly influenced the point of view on PMO.

In order to recognize PMO quickly and easily, we developed and validated a new instrument, the "Mini Questionnaire of Personal Organization" (MQPO; Nardi et al., 2012). It is a new self-report questionnaire, quick and easy to use (see Table 2). The theoretical construct behind the questionnaire makes it especially an original instrument, according to the adaptive-evolutionary approach above discussed. The MQPO investigates the physiological and adaptive characteristics of the PMO. Moving from inward/outward distinction, the questionnaire construction is targeted to the classification in the four PMO through four different scales: Contextualized, Controller, Principle-Oriented, and Detached. The questionnaire items are complex and aimed to investigate cognitive and emotional elements, these are strongly bound together in the immediacy of experience. Nevertheless, this complexity is high because it depends on subjective interpretation on the item and on own ability to observe and know himself/herself. Initially we created a set of 40 items; then we reduced them to 29 items. Lastly, the MQPO included 20 items (5 sentences/items for each scale). 
Table 2. The Mini Questionnaire of Personal Organization “MQPO” (Nardi et al., 2012)

\begin{aligned} & \hline 1 I feel myself adequate, I don't disappoint other's expectations \\ & 2 I have a feeling of constriction when I cannot move freely \\ & 3 The commitment I put in doing things makes me feel good, rather than others' appreciation \\ & 4 For me loneliness is the basic life condition \\ & 5 It's important for me to understand if I have other's approval \\ & 6 I feel free and not constricted when I have the situation under control \\ & 7 To feel myself fair and impartial, I take into consideration more my internal rules more than \\ & 8 other's opinion \\ & 9 I generally think that I am alone and that there is a great distance between me and others \\ & 10 When I feel controlled, I generally feel myself constricted and not free rather than disregarded \\ & 11 I usually don't change my opinion when I am criticized by others \\ & 12 I feel that I cannot rely on anyone, so I must strongly commit myself to face reality, since \\ & results only depend on me \\ & 13 I feel embarrassed and inadequate when the others criticize me \\ & 14 It's essential for me to be able to come in and out freely from a situation \\ & 15 In doubt situations, others' opinions are less important than mine \\ & 16 To be successful in life, one must strongly commit him/herself facing his/her destiny of \\ & 17 loneliness \\ & 18 I feel myself important if I am appreciated and required by others \\ & 19 When I have a doubt, I tend to ignore other's expectations \\ & 20 In my life I always had to shift for myself, as I cannot count on other's help \\ & \hline\end{aligned}

At this moment, for the validation of MQPO a sample of 296 subjects was tested (mean age $=35.3, \mathrm{SD}=12.0$ ): 108 males (mean age $=37.5, \mathrm{SD}=12.9$ ) and 188 females (mean age $=34.1, \mathrm{SD}=11.3$ ). The results showed that MQPO was consistent with the post-rationalist paradigm. Four different factors have been found from the items of the questionnaire, one for each PMO. By means of the Factor Analysis, in fact, four factors explaining the $42.21 \%$ of the total variance were extracted with the use of the maximum likelihood extraction method and the Varimax rotation's method with Kaiser normalization. The observation of the factorial matrix showed that the different items analyzed had a good correlation with the factor that represent their own PMO, while there were not high correlation indexes with factors that represent different PMO. The internal homogeneity of the scales was tested with the item-total Correlation Analysis by means of Pearson correlation analysis. The average inter-item correlation was adequate for each scale of the questionnaire. The internal validity was evaluated by means of Cronbach's alpha. This analysis showed good internal reliability index for the total score (alpha $=.73$ ), and for each scale (Controller PMO scale alpha $=.78$, Contextualized PMO scale alpha $=.78$, Principle-Oriented PMO scale alpha $=.68$, Detached PMO scale alpha $=.77)$. Moreover, results of test reliability were measured by means of correlation analysis and were stable across time for the four scales (from $r=.80$ to $r=.89$ ). The Discriminant Validity was evaluated using the external shared diagnosis of two different experts through the "moviola" setting interviews. It showed that the $72.5 \%$ of the sample was correctly classified (i.e., the subjects were assigned to the same profile of the external diagnosis used as reference). We found an excellent agreement ( $80.0 \%$ overlap) using as reference the classification obtained by the PMQ (Picardi, 2003). This calculation of the discriminant function was done by means of PMQ classification (used as independent variable) and the four MQPO scales scores (used as dependent variables). Despite some theoretical construct differences between MQPO and PMQ, we obtained a better convergence than the clinical evaluation. The agreement between the two instruments is mainly due to their self-report form. Every self-report instrument is more influenced by 
motivation to reply, social desirability, introspection (Kline, 1993) and, in particular, by experience explanations and self-deception mechanisms that make it less effective in investigating emotions.

As described above, emotions should be investigated and regarded in the therapeutic work, in order to specify the process-oriented development and stabilization of individual's personality (PMO). At the moment, the best way is the "moviola" setting because it allows to understand the immediacy of experience and the subjective point of view on it. For this reason, we are conceiving a tool still more innovative and original than MQPO. Recently we have developed a project in order to focus on the emotions experienced and perceived by a subject to investigate PMOs in a standardized way, overcoming some MQPO limitations and catalyzing our research efforts over the past two years. An apperceptive test was developed and is currently under validation: the Post-Rationalist Projective Reactive (PRPR; see Figure 2). The test is based on the view of twenty scenes. The respondent has to invent a story for each of them.

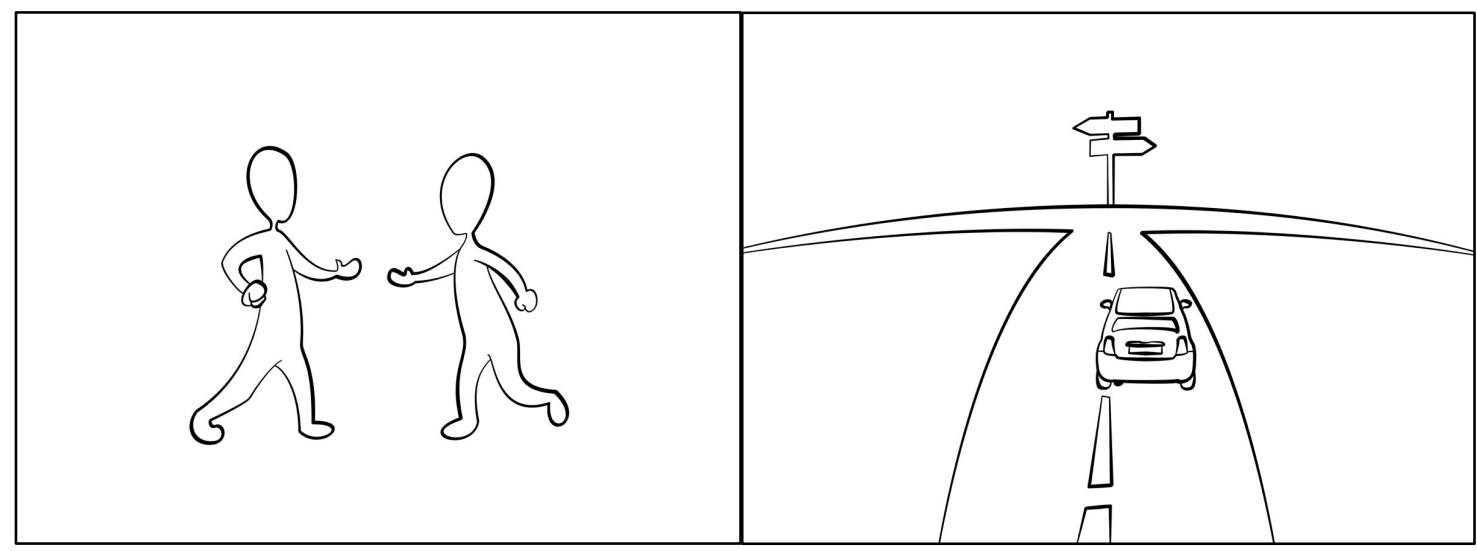

Figure 2. Two PRPR pictures (scene 1 and scene 16) (Arimatea E., Vernice M., \& Nardi B., 2012)

The stimuli present two main features. A) Black and white drawing sketches are neutral and impersonal as much as possible. B) Each scene refers to a relational context: individual relationship (to himself / herself), asymmetrical relationship (adult - child) relationship with the group, relationship with the natural environment and relationship with the opposite sex.

Each scene was conceived on elements that can be traced to every organization. Therefore, we do not expect a unique correspondence between a scene and a specific PMO. The developed method involves a standardized criteria for evaluating responses and a careful analysis of the stories. The scorer needs to give a rating with respect to three scales (Emotion, Reciprocity and Intensity). The combination of the scores in these three scales identifies the invariant features characterizing a specific PMO. The PRPR is proposed as a test about emotions. The subject must assume the role of stories director, not the critical or moralizer role, because these ones are related to the explanation level of his/her own stories. In other terms, PRPR allows the subject to deepen the specific narrative plots of his/her personality and figure out the internal movie of the individual in order to focus his/her subjective feelings.

The preliminary results of PRPR's validation showed good results and an acceptable internal consistency. A sample of 111 subjects (43 males and 68 females, mean age: 30.89 years, $\mathrm{SD}=13.70$, age range 19-71 years) was tested. The PRPR internal validity was assessed by means of Cronbach's alpha. The internal consistency of items in the three scales was acceptable (alpha from .70 to .84). A cluster analysis was conducted to examine the distribution of scores in the scales with regard to the PMO classification (Everitt, Landau \& Leese, 2001). Cluster analysis allows to create stable and objective classifications in groups of subjects whose score patterns are similar in all the scales of the test (Aldenderfer \& Blashfield, 1984). Cluster analysis indicated the presence of four clusters that overlap with the theoretical description of PMO. Furthermore, there were statistically significant convergent validity correlations with the MQPO $(\mathrm{r}=.53, \mathrm{p}<.001 ; 65 \%$ overlap) and better with the clinical evaluation using the external shared diagnosis of two different experts through the "moviola" setting interviews ( $\mathrm{r}=.97, \mathrm{p}<.001 ; 88 \%$ overlap). This outcome indicates that PRPR actually can be a reliable tool, providing results close to those obtained by means of the "moviola" setting interview. Finally, such preliminary results support the theory of PMO (Arimatea, Vernice \& Nardi, 2012), in line with the subjective evolutional-adaptive post-rationalist approach. 


\section{Conclusions}

As mentioned above, progress in neuroscience allows to find new lines of research, to highlight biological correlations for personality patterns, like those individuated in the paradigm of PMO. Thanks to new technologies, it is possible to observe that useful psychotherapeutic approaches, like the post-rationalist cognitive therapy, have not only solid theoretical and epistemological bases, but are also confirmed by specific neural patterns (i.e., biological differences in emotional activation between inward or outward subjects), and genetic polymorphisms configurations; such facts can explain how attachment processes not only have a learned bases, but are also driven by behavioural genetic patterns.

In conclusion, progresses in neuroscience can be useful to validate psychotherapeutic paradigms (not only the "rationalist" ones, but the "post-rationalist" ones too), as well as to throw light on what happens in the mind as a consequence of psychotherapy, and can enact the connection between biological (i.e., psychopharmacology) and psychological (i.e., psychotherapy) approaches to mental disorders.

\section{References}

Abelson, R. P. (1981). Psychological status of the script concept. American Psychologist, 36, 715-29. http://dx.doi.org/10.1037/0003-066X.36.7.715

Aldenderfer, M. S., \& Blashfield, R. K. (1984). Cluster Analysis (Vol. 07-044). London: SAGE Publications Ltd.

Arimatea, E., Vernice, M., \& Nardi, B. (2012). Il Post-Rationalist Projective Reactive "PRPR": validazione preliminare del primo test proiettivo post-razionalista. (Abstract in English). Quaderni di Psicoterapia Cognitiva SITCC, 29(2).

Bertolino, A., Arciero, G., Rubino, V., Latorre, V., De Candia, M., Mazzola, V., Blasi, G., Cario, G., Hariri, A., Kolashana, B., Nardini, M., Weinberger, D. R., \& Scarabino, T. (2005). Variation of the human amygala response during threatening stimuli as a function of 5'HTTLPR genotype and personality style. Biological Psychiatry, 57, 1517-25. http://dx.doi.org/10.1016/j.biopsych.2005.02.031

Breiter, H. C., Etcoff, N. L., Whalen, P. J., Kennedy, W. A., Rauch, S. L., Buckner, R. L., Strauss, M. M., Hyman, S. E., \& Rosen, B. R. (1996). Response and habituation of the human amygdala during visual processing of facial expression. Neuron, 17, 875-87. http://dx.doi.org/10.1016/S0896-6273(00)80219-6

Costafreda, S. G., Brammer, M. J., David, A. S., \& Fu, C. H. (2008). Predictors of amygdale activation during the processing of emotional stimuli: A meta-analysis of 385 PET and fMRI studies. Brain Research Revue, 12, 57-70. http://dx.doi.org/10.1016/j.brainresrev.2007.10.012

Damasio, A. R. (1999). The Feeling of What Happens. Body and Emotion in the Making of Consciousness. San Diego: Harcourt.

Everitt, B. S., Landau, S., \& Leese M. (2001). Cluster Analysis. London: Arnold.

Guidano, V. F. (1987). The Complexity of the Self. New York: Guilford.

Guidano, V. F. (1991a). The Self in Progress. New York: Guilford.

Guidano, V. F. (1991b). Affective change events in a cognitive therapy system approach. In J. D. Safran \& L. S. Greenberg (Eds.), Emotion, Psychotherapy and Change. New York: Guilford.

Guidano, V. F. (1995). Constructivistic psychotherapy: A theoretical framework. In R. A. Neimeyer \& M. J. Mahoney (Eds.), Constructivism in Psychotherapy. Washington: American Psychological Association.

Guidano, V. F., \& Liotti, G. (1983). Cognitive Processes and Emotional Disorders. New York: Guilford.

Kline, P. (1993). The Handbook of Psychological Testing. London: Routledge.

Mazzola, V., Latorre, V., Petito, A., Gentili, N., Fazio, L., Popolizio, T., Blasi, G., Arciero, G., \& Bondolfi, G. (2010). Affective response to a loved one's pain: insula activity as a function of individual differences. PLoS ONE, 5(12). http://dx.doi.org/10.1371/journal.pone.0015268

Morris, J., Frith, C., Perret, D. Rowland, D., Young, A. W., Calder A. J., \& Dolan, R. J. (1996). A differential neural response in the human amygdale to fearful and happy facial expressions. Neuropsychologia, 42, 1029-40. http://dx.doi.org/10.1038/383812a0

Nardi, B. (2007). CostruirSi. Sviluppo e Adattamento del Sé nella Normalità e nella Patologia. Milano: Franco Angeli.

Nardi, B. (2010). Guidelines on the construction of a post-rationalist therapeutic approach. European 
Psychotherapy, 9(1), 57-67.

Nardi, B., Arimatea, E., Giovagnoli, S., Blasi, S., Bellantuono, C., \& Rezzonico, G. (2012). The Mini Questionnaire of Personal Organization (MQPO): preliminary validation of a new post-rationalist personality questionnaire. Clinical Psychology and Psychotherapy, 19, 78-90. http://dx.doi.org/10.1002/CPP.740

Nardi, B., \& Bellantuono, C. (2008). A new adaptive and evolutionary conceptualization of the Personal Meaning Organization (P.M.O.) framework. European Psychotherapy, 8(1), 5-16.

Nardi, B., Capecci, I., Fabri, M., Polonara, G.., Mascioli, G.., Cavola, G., Di Nicolò, M., Laurenzi, S., Rocchetti, D., Brandoni, M., Rocchetti, G., Salvolini, U., Manzoni, T., \& Bellantuono, C. (2008a). fMRI investigation of emotional activations during visual processing of other or own facial expressions in subjects with inward or outward personality. Rivista di Psichiatria, 43(4), 233-41. http://dx.doi.org/10.1708/397.4683

Nardi, B., Capecci, I., Fabri, M., Polonara, G., Salvolini, U., Bellantuono, C., \& Moltedo, A. (2008b). Estudio mediante imagen funcional de resonancia magnética (fMRI) de las activaciones emotivas correlacionadas a la presentación de rostros extraños o del propio rostro en sujetos con personalidad inward y outward. Revista Chilena de Neuropsiquiatría, 46(3), 168-181. http://dx.doi.org/10.4067/S0717-92272008000300002

Nardi, B., Piva, F., Turchi, C., Cedraro, M., Arimatea, E., Giulietti, M., Principato, G., Tagliabracci, A., \& Bellantuono, C. (2011a). Genetic factors in inward vs outward personality organizations: focus on HTR2A polymorphisms. Quaderni Italiani di Psichiatria, 30(2), 83-88. http://dx.doi.org/10.1016/j.quip.2011.04.001

Nardi, B., Piva, F., Turchi, C., Giulietti, M., Castellucci, G., Arimatea, E., Rocchetti, D., Rocchetti, G., Principato, G., Tagliabracci, A., \& Bellantuono, C. (2011b). HTR2A gene polymorphisms and Inward and Outward Personal Meaning Organizations. Acta Neuropsychiatrica. http://dx.doi.org/10.1111/j.1601-5215.2011.00644.x

Nardi, B., Turchi, C., Piva, F., Giulietti, M., Castellucci, G., Arimatea, E., Rocchetti, D., Rocchetti, G., Principato, G., Tagliabracci, A., \& Bellantuono, C. (2011c). Searching for a relationship between the serotonin receptor $2 \mathrm{~A}$ gene variations and the development of Inward and Outward Personal Meaning Organizations. Psychiatric Genetics, 21(5), 269-270. http://dx.doi.org/10.1097/YPG.0b013e32834371bc

Nardi, B., Rezzonico, G., \& Bellantuono, C. (2010). Toward a scientific framework for the Personal Meaning Organization (PMO) paradigm: neuroimaging and genetic studies. Quaderni Italiani di Psichiatria, 29(3), 81-88. http://dx.doi.org/10.1016/j.quip.2010.07.003

Pérez-Edgar, K., Roberson-Nay, R., Hardin, M. G.., Poeth, K., Guyer, A. E., Nelson, E. E., McClure, E. B., Henderson, H. A., Fox, N. A., Pine, D. S., \& Ernst, M. (2007). Attention alters neural responses to evocative faces in behaviorally inhibited adolescents. NeuroImage, 35(4), 1538-46. http://dx.doi.org/10.1016/j.neuroimage.2007.02.006

Phillips, M. L., Young, A. W., Scott, S. K., Calder, A. J., Andrew, C., Giampietro, V., Williams, S. C. R., Bullmore, E. T., Brammer, M., \& Gray, A. (1998). Neural responses to facial and vocal expressions of fear and disgust. Proceeding of the Royal Society London Bulletin of Biological Sciences, 265, 1809-1817. http://dx.doi.org/10.1098/rspb.1998.0506

Picardi, A. (2003). First steps in the assessment of cognitive emotional organization within the framework of Guidano's model of the self. Psychotherapy and Psychosomatics, 72, 363-365. http://dx.doi.org/10.1159/0000730

Piva, F., Giulietti, M., Nardi, B., Bellantuono, C., \& Principato, G. (2010). An improved in silico selection of phenotype affecting polymorphisms in SLC6A4, HTR1A and HTR2A genes. Human Psychopharmacology, 25(2), 153-161. http://dx.doi.org/10.1002/hup.1100

Pribram, K. H. (1971). Languages of the Brain. Englewood Cliffs (N. J.): Prentice-Hall.

Prigogine, I. (1980). From Time to Becoming: Time and Complexity in the Physical Sciences. San Francisco: Freeman.

Rubino, V., Blasi, G., Latorre, V., Fazio, L., d'Errico, I., Mazzola, V., Caforio, G., ... Bertolino, A. (2007). Activity in medial prefrontal cortex during cognitive evaluation of threatening stimuli as a function of personality style. Brain Research Bulletin, 74(4), 250-257. http://dx.doi.org/10.1016/j.brainresbull.2007.06.019

Sameroff, A. J. (1982). Development and the dialectic: the need for a systems approach. In W. A. Collins (Ed.). The Concept of Development. Hillsdale (N. J.): Erlbaum

Schulte-Rüther, M., Markowitsch, H. J., Fink, G. R., \& Piefke, M. (2007). Mirror neuron and theory of mind 
mechanisms involved in face-toface interactions: a functional magnetic resonance imaging approach to empathy. Journal of Cognitive Neuroscience, 19(8), 1354-72. http://dx.doi.org/10.1162/jocn.2007.19.8.1354

Tomkins, S. S. (1978). Script theory: Differential magnification of affects. In: H. E. Howe \& M. M. Page (Eds.), Nebraska Symposium on Motivation. Lincoln: University of Nebraska Press.

Weimer, W. B. (1979). Notes on the Methodology of Scientific Research. Hillsdale (N. J.): Erlbaum.

Weimer, W. B. (1982). Ambiguity and the future of psychology: meditations leibniziennes. In W. B. Weimer \& D.S. Palermo (Eds.), Cognition and the Symbolic Processes (Vol. 2). Hillsdale (N. J.): Erlbaum.

Whalen, P. J., Rauch, S. L., Etcoff, N. L., McInerney, S. C., Lee, M. B., \& Jenike, M. A. (1998). Masked presentations of emotional facial expressions modulate amygdala activity without explicit knowledge. Journal of Neurosciences, 18(1), 411-8.

Whalen, P. J., Shin, L. M., Mc Inerney, S. C., Fischer, H., Wright, C. I., \& Rauch, S. L. (2001). A functional MRI study of human amygdala responses to facial expressions of fear versus anger. Emotion, 1(1), 70-83. http://dx.doi.org/10.1037/1528-3542.1.1.70

Wang, L., Mc Carthy, G., Song, A. W., \& Labar, K. S. (2005). Amygdale activation to sad pictures during high-field (4 Tesla) functional magnetic resonance imaging. Emotion, 5(1), 12-22. http://dx.doi.org/10.1037/1528-3542.5.1.12

Vogeley, K., Schneider-Axmann, T., Pfeiffer, U., Tepest, R., Bayer, T. A., Bogerts, B., Honer, W. G., \& Falkai, P. (2000). Disturbed gyrification of the prefrontal region in male schizophrenic patients: A morphometric postmortem study. American Journal of Psychiatry, 157, 34-39.

Vuilleumier, P., Armony, J. L., Driver, J., \& Dolan, R. J. (2003). Distinct spatial frequency sensitivities for processing faces and emotional expressions. Nature Neuroscience, 6(6), 624-631. http://dx.doi.org/10.1038/nn1057 